\title{
PREFACE TO THE SEVENTH AND EIGHTH GERMAN EDITION
}

The sixth edition of this book was so well received at home and abroad in spite of its unusual size, that two reprints were necessary. In his endeavor to improve the subject matter of this combined edition, the author has increased the length and scope of each chapter so as to present as nearly as he could, a complete picture of our present objective knowledge. Thus the text has been enriched in many directions, particularly from experiences acquired during the World War.

An esteemed friend, a specialist in this line, was kind enough to say that the author had produced not merely a good text book with the didactic advantage of uniform conception and presentation, but a book suitable for reference by any one who required for whatever reason, a concise text book of special pathological anatomy; others were good enough to concur in this opinion. Students of medicine are always foremost in the author's mind, and thus the subjects which he regards as the most important for those who are to be our physicians, have been handled with special insistence and with detail; to complete the viewpoint, make it clearer to the understanding and at the same time to maintain interest, excursions are made into embryology, anatomy, physiology and general pathology.

Faithful to the thought that was expressed in the first edition of this work, the close connection between pathological anatomy and practical medicine, or between theory and practice, is emphasized by numerous references to clinical data. Readers who desire more details in any subject or who wish to trace all the sources, will, I hope, find the road well mapped out by the details in the text and by the references to the literature.

The number of illustrations is increased by several hundred, most of them from sketches made by the author of specimens in the Pathological Institute of Basle and in the collection at Gottingen. A number were also obtained from plates published in Virchow's Archives. Volume 3 contains the index and references to the literature which have been increased by many thousands. Although the latter occupies considerable space, this wealth of literature is indispensable in the opinion of his colleagues, Prof. Pio Foa and Prof. Sapegno, editors of the Italian translation of the book; the author. therefore. has not shirked the labor of its further extension; to ensure the utmost reliability he has included only such works as he himself has checked. 
The author expresses his thanks to many colleagues in pathology and to numerous clinicians and specialists in other lines both at home and abroad for their kindness in sending him monographs and reprints; he hopes that this help will be forthcoming in the future also.

To Drs. Staemmler and Husten, the author also tenders his thanks for their valuable help in the preparation of the book.

EDWARD KaUfManN.

GotringeN 